\title{
PREVALENCE AND CORRELATES OF PATERNAL POSTPARTUM DEPRESSION IN SAUDI ARABIA
}

Waleed A. Alghamdi ${ }^{1}$, Huda Y. Alyahyawi' ${ }^{1}$ Saeed S. Shaaban², Rame S. Alharbi², Bassam E. Yaghmoor ${ }^{2}$, Sara F. Alnajjar², Hussein M. Alshamrani²

1'Department of Psychiatry, Faculty of Medicine, King Abdulaziz University, Jeddah, Saudi Arabia

${ }^{2}$ Department of Medicine, Faculty of Medicine, King Abdulaziz University, Jeddah, Saudi Arabia

Corresponding Author: Dr. Saeed Sami Shaaban: saeedalfehri@gmail.com

Submitted: 19 October 2019. Accepted: 27 February 2020. Published: 19 March 2020.

\section{ABSTRACT}

\section{Background and objective}

Literature concerning paternal postpartum depression (PPPD) is rare. However, PPPD is a highly relevant disorder and can have a detrimental effect on the well-being of the family. Paternal care is an essential factor for infants' mental development, and PPPD has been clearly shown to influence infants' psychopathology and behavior later in life. This preliminary study aimed to detect the prevalence of PPPD and the correlated demographic and socioeconomic factors in fathers to newborns at the King Abdulaziz University Hospital (KAUH) in Jeddah, Saudi Arabia.

\section{Materials and methods}

This was a cross-sectional study conducted at KAUH in Jeddah, Saudi Arabia, between January 1, 2017 and June 25, 2018. We collected data telephonically through questionnaires based on previous studies. A PPPD cutoff score of $>10$ using a validated Arabic translation of the Edinburgh Postpartum Depression Scale was used. We enrolled 150 fathers with a mean age of $36.61 \pm 7.72$ years in the study.

\section{Results}

The results showed that more than a quarter $(27.3 \%)$ of the participants suffered from PPPD. Factors that correlate with PPPD included a weak relationship with the paternal/mother $(\mathrm{p}=0.001)$, trouble sleeping $(\mathrm{p}=0.010)$, lower self-esteem $(\mathrm{p}=0.012)$, family-related problems $(p<0.0001)$, work-related problems $(p=0.002)$, work-family conflict $(p<0.0001)$, and perceived perinatal and postpartum stress ( $\mathrm{p}=0.001$ and $<0.0001$ respectively). 


\section{Conclusions}

The results confirm that PPPD is prevalent among fathers in Jeddah. Screening for and treatment of PPPD in Saudi Arabia is currently lacking, and the prevalence of PPPD according to these findings indicates that these deficiencies urgently need to be addressed. Counselling and support for managing health, family, and work issues during and after pregnancy could contribute to preventing PPPD.

Key Words: paternal postpartum depression (PPPD); depression; Jeddah; Edinburgh Postnatal Depression Scale; men's health

\section{INTRODUCTION}

Depression, which can affect many aspects of an individual's daily life, is a widespread global disorder that affects more than 300 million people. Approximately 800,000 individuals die every year from depression-related disorders, and depression is predicted to be one of the leading diseases, on a global scale, by 2030. ${ }^{1,2}$ Despite these numbers, stigmatization around depressive disorders still persists. ${ }^{3}$

Postpartum depression (PPD) is defined as moderate to severe depression diagnosed during the postpartum period, that is, shortly followingand up to 1 year after - childbirth. ${ }^{4}$ Symptoms include restlessness, sudden mood swings, thoughts of self-harm, and thoughts of causing harm to the infant. ${ }^{3}$ Maternal PPD has been extensively studied and is found to affect up to $11 \%$ of women worldwide. ${ }^{5}$ Contrastingly, literature pertaining to paternal postpartum depression (PPPD) is scarce, although PPPD cases are on the rise. ${ }^{6}$ Recent studies have shown mixed results in the estimated incidences of PPPD in the first year postpartum, ranging from $1.7 \%$ to $31.1 \%$, and averaging around $8 \% .^{7}$ This variation may be caused by different cut-off points, sample sizes, and cultural backgrounds. ${ }^{8}$

No definite biological cause for PPPD has been found. However, there have been a number of theories concerning hormonal changes - such as low testosterone, estrogen, or prolactin, among others-which could lead to mood swings. Furthermore, psychosocial risk factors, maternal
PPD, familial and sexual issues, work issues, and the lack of a paternal role model have all been found to pose an increased risk. ${ }^{9}$ According to recent studies, poor self-esteem and work-family conflicts are significant risk factors at 6 weeks postpartum. Social support was found to be a significant factor in late pregnancy and at 2 weeks postpartum. ${ }^{10,11}$ Other risk factors - such as unplanned pregnancy, low income, and marital dissatisfaction - did not achieve statistical significance at all levels. ${ }^{10}$

The significance of PPPD is rooted in its detrimental effect on the family. The father's early interactions with the infant have been proven to be as important as the mother's. ${ }^{12}$ Moreover, paternal care is essential to an infant's mental development, and thus PPPD has been shown to be a risk factor for psychopathology and behavioral problems later in the infant's life. ${ }^{13}$ Depressed fathers are able to establish a secure relationship with their infants to a lesser extent, making the infant more susceptible to insecure attachments later on in life ${ }^{14}$ and possibly harming the infant's relationship with its mother. The father's depressed condition may also lead to a failure to compensate for the mother's possible existing depressive state due to fathers' inability to provide support, increasing the mothers' vulnerability to psychological stressors. ${ }^{15}$ Lastly, PPPD may lead to the abuse or neglect of the infant, just as PPD may. ${ }^{9,16}$

Limited data concerning the prevalence and the associated factors of PPPD are available in the Middle East. Saudi Arabia, specifically, is unique because of its cultural and social structure and the 
role of the father in the family, making it an area of specific interest for our study. A study conducted in Riyadh, Saudi Arabia, showed that $16.6 \%$ of the respondents suffered from PPD. ${ }^{17}$ Moreover, in neighboring Egypt, another study showed a prevalence of $31.4 \% .^{18}$ The role of patriarchy in Saudi culture - where the father is mainly, if not entirely, responsible for providing for the family - is also a relevant factor. The study conducted in Riyadh showed that a father's employment situationwhether he has a permanent or a temporary position and the amount of time spent at work - were significant factors in the diagnosis of PPPD. ${ }^{17} \mathrm{In}$ addition to these factors, the stigma concerning mental illness still often prevents sufferers from seeking help. This is particularly true for the patriarch of the family, as others may see them as "weak" or "incompetent" if they do decide to seek help. ${ }^{19,20}$

This study aims to fill some of the gaps concerning PPPD data and to take the first step for future studies regarding PPPD in various regions of the country. We accomplish this by examining the prevalence of PPPD as well as the correlated demographic and socioeconomic factors in fathers at the King Abdulaziz University Hospital in Jeddah, Saudi Arabia.

\section{METHODS}

This was a cross-sectional study conducted at King Abdulaziz University Hospital (KAUH) in Jeddah, Saudi Arabia. Fathers of newborns were recruited and interviewed telephonically over a period between January 1, 2017 and June 25, 2018. King Abdulaziz University Hospital is one of the biggest teaching centers in the western region of Saudi Arabia, with an 800-bed capacity. Ethical approval was obtained from the Institutional Review Board (IRB) of King Abdulaziz University Hospital.

\section{Selection of Participants}

We collected 461 data profiles of parents of newborns. Out of this sample, only 182 fathers conformed to the study's inclusion criteria, which were: (1) having a newborn between 4 and 8 weeks of age, (2) ability to communicate in Arabic, and (3) age of at least 18 years. Some fathers who did meet these criteria refused to participate, and there was a high turnover of phone numbers. We excluded 32 of the 182 eligible participants due to missing information and a timing cut-off. Interviewers contacted eligible participants over the telephone. After assuring respondents that all information would be confidential, fathers' verbal consent was obtained before continuing with the questionnaire.

\section{Measurement of Paternal Depression}

To collect demographic data and other variables, we used a questionnaire based on previous studies ensuring that the questions were posed in a culturally appropriate way. We also used the Edinburgh Postnatal Depression Scale (EPDS), a self-administered survey that consists of 10 items, with each item rated from 1 to 4 to assess the severity of PPD. Higher scores reflect a higher level of symptom severity. ${ }^{21}$ The EPDS has been translated into several languages and has been validated in many cultures. It is the most commonly-used measure to determine depressive symptoms among mothers in the postpartum period and to screen for paternal depression among fathers. ${ }^{22}$ It has also been reported to be a valid and reliable tool in Arabic. ${ }^{23}$ A recommended cut-off score of 10 points or more was considered to indicate probable PPPD and a consequent need for further evaluation. ${ }^{22}$ The chosen cutoff elicited a sensitivity of $91 \%$ and a specificity of $84 \%$. The Cronbach's alpha for the EPDS is $0.84^{23}$ in the Arabic scale, similar to another existing study. ${ }^{22}$

\section{Measurements of Risk Factors and Other Variables}

The demographics questionnaire was formulated based on previous studies. ${ }^{7,810}$ Factors such as age, marital status, level of education, monthly income, occupation, and hours worked per day 
were obtained. The questionnaire also included psychosocial risk factors such as quality of relationship with partner/infant's mother, marital satisfaction, planned/unplanned pregnancy, selfesteem, gender preference of infant, number of children, work-family conflict, history of paternal or maternal depression, trouble sleeping, and diseases in the father or the child.

\section{Statistical Analysis}

The data were entered into an excel sheet and then converted to SPSS (version 21) data for further analysis. The categorical variablesincluding primary variables-were described using a frequency table. Continuous variables for normal distribution were described using mean, standard deviation, and range. The data were then processed to determine statistical significance using a chi-squared test. For all statistical analyses, $\mathrm{p}$-values lower than 0.05 were considered to be significant.

\section{RESULTS}

A sample of 182 fathers participated in both the EPDS and the demographic factors questionnaire. After the answers of 32 fathers were excluded owing to them not fulfilling the inclusion criteria, 150 fathers' completed questionnaires were included in the analysis.

The mean age of the fathers was $36.61( \pm 7.72)$ years and the ages of the infants ranged from the 4th to the 8th week after birth. From amongst the sample, $23.3 \%$ of the respondents were firsttime parents. The median income of the respondents was between Saudi Riyal (SAR) 7,001 and SAR 15,000, similar to the average family income range in Saudi Arabia. Concerning education, 73 of the fathers held a bachelor's degree, 54 held a high-school diploma, 14 held a post-graduate degree, five held a middle school diploma, three held an elementary school diploma, and one did not attend school. Regarding employment, 140 of the fathers were employed and only 10 were unemployed. Two of the fathers reported having a poor relationship with the partner/infant's mother and five had a history of depression. Lastly, according to the respondents, five of the respondents' partners had a history of depression.

A score of 10 points or higher was set as the cutoff point to screen for PPPD. According to this cutoff, $27.3 \%$ of the respondents were considered to have PPD. A comparison of the correlated factors was conducted between fathers with and without PPPD.

Factors such as nationality $(\mathrm{p}=0.144)$, occupation $(p=0.402)$, education level $(p=0.289)$, monthly income $(p=0.970)$, and being a firsttime parent $(p=0.402)$ showed no correlation between those with depression and those without. Table 1 presents all of the variables used in the research.

The respondents with a score above 10 reported experiencing sleep problems $(\mathrm{p}=0.010)$, self-esteem issues $(\mathrm{p}=0.012)$, family problems ( $\mathrm{p}=0.00001)$, work problems $(\mathrm{p}=0.002)$, and conflicts between work and family life $(p=0.000034)$. Table 2 shows the factors with significant $\mathrm{p}$-values. Fathers who reported having a poor relationship with the partners/infant's mothers $(p=0.001)$ were significantly more likely to be depressed. Moreover, fathers with perceived stress during or after pregnancy $-(p=0.001)$ and $(p=0.00002)$ respectively - were significantly more depressed. Fathers who had better knowledge of the newborns' $(p=0.047)$ or wives' $(p=0.038)$ health status were less likely to have PPPD.

\section{DISCUSSION}

This research addressed the issue of PPPD in fathers in the Middle East, specifically Saudi Arabia. Its goal was to determine the prevalence and associated correlates of PPPD from among a sample of fathers in Jeddah, Saudi Arabia. The research was conducted by making use of a telephonic questionnaire with a sample of fathers 
TABLE 1 Factors Related to Paternal Postpartum Depression Measured Using Chi-Squared Test $(\mathrm{n}=150)$

\begin{tabular}{|c|c|c|c|}
\hline \multirow{3}{*}{ Studied factors } & \multicolumn{2}{|c|}{ PPPD (\% within factor) } & \multirow{3}{*}{ p-value } \\
\hline & $\begin{array}{l}\text { No depression } \\
\text { based on EPDS }\end{array}$ & $\begin{array}{c}\text { Depression } \\
\text { based on EPDS }\end{array}$ & \\
\hline & $(n=109,72.7 \%)$ & $(n=41,27.3 \%)$ & \\
\hline Nationality & & & 0.128 \\
\hline Saudi & $85(75.9 \%)$ & $27(24.1 \%)$ & \\
\hline Non-Saudi & $24(63.2 \%)$ & $14(36.8 \%)$ & \\
\hline Occupation & & & 0.402 \\
\hline Government & $63(77.8 \%)$ & $18(22.2 \%)$ & \\
\hline Private & $39(67.2 \%)$ & $19(32.8 \%)$ & \\
\hline Unemployed & $6(60 \%)$ & $4(40 \%)$ & \\
\hline Student & $1(100 \%)$ & $0(0 \%)$ & \\
\hline Education level & & & 0.289 \\
\hline None & $0(0 \%)$ & $1(100 \%)$ & \\
\hline Elementary school & $2(66.7 \%)$ & $1(33.3 \%)$ & \\
\hline Middle school & $5(100 \%)$ & $0(0 \%)$ & \\
\hline High school & $39(72.2 \%)$ & $15(27.8 \%)$ & \\
\hline College & $51(69.9 \%)$ & $22(30.1 \%)$ & \\
\hline Post graduate & $12(85.7 \%)$ & $2(14.3 \%)$ & \\
\hline Monthly income & & & 0.97 \\
\hline$<$ SAR 3,000 & $11(68.8 \%)$ & $5(31.3 \%)$ & \\
\hline SAR 3,001-5,000 & $17(70.8 \%)$ & $7(29.2 \%)$ & \\
\hline SAR 5,001-7,000 & $25(73.5 \%)$ & $9(26.5 \%)$ & \\
\hline SAR 7,001-15,000 & $41(71.9 \%)$ & $16(28.1 \%)$ & \\
\hline$>$ SAR 15,000 & $15(78.9 \%)$ & $4(21.1 \%)$ & \\
\hline Currently smoking & & & 0.621 \\
\hline No & $66(74.2 \%)$ & $23(25.8 \%)$ & \\
\hline Yes & $43(70.5 \%)$ & $18(29.5 \%)$ & \\
\hline Work hours per day & & & 0.309 \\
\hline$<6$ hours & $21(75 \%)$ & $7(25 \%)$ & \\
\hline $6-8$ hours & $50(79.4 \%)$ & $13(20.6 \%)$ & \\
\hline $8-10$ hours & $26(63.4 \%)$ & $15(36.6 \%)$ & \\
\hline$>10$ hours & $12(66.7 \%)$ & $6(33.3 \%)$ & \\
\hline Postpartum vacation & & & 0.097 \\
\hline No & $55(73.3 \%)$ & $20(26.7 \%)$ & \\
\hline$<1$ week & $26(61.9 \%)$ & $16(38.1 \%)$ & \\
\hline $1-2$ weeks & $14(73.7 \%)$ & $5(26.3 \%)$ & \\
\hline
\end{tabular}


TABLE 1 Related to Paternal Postpartum Depression Measured Using Chi-Squared Test ( $\mathrm{n}=150)$ (Continued)

\begin{tabular}{|c|c|c|c|}
\hline \multirow{3}{*}{ Studied factors } & \multicolumn{2}{|c|}{ PPPD (\% within factor) } & \multirow{3}{*}{ p-value } \\
\hline & \multirow{2}{*}{$\begin{array}{c}\begin{array}{c}\text { No depression } \\
\text { based on EPDS }\end{array} \\
(n=109,72.7 \%) \\
\end{array}$} & \multirow{2}{*}{$\begin{array}{c}\begin{array}{c}\text { Depression } \\
\text { based on EPDS }\end{array} \\
(n=41,27.3 \%) \\
\end{array}$} & \\
\hline & & & \\
\hline 2-4 weeks & $10(100 \%)$ & $0(0 \%)$ & \\
\hline$>4$ weeks & $4(100 \%)$ & $0(0 \%)$ & \\
\hline Previously diagnosed with depression & & & 0.614 \\
\hline No & $106(73.1 \%)$ & $39(26.9 \%)$ & \\
\hline Yes & $3(60 \%)$ & $2(40 \%)$ & \\
\hline Wife previously diagnosed with depression & & & 0.02 \\
\hline No & $108(74.5 \%)$ & $37(25.5 \%)$ & \\
\hline Yes & $1(20 \%)$ & $4(80 \%)$ & \\
\hline Subjective depressive feelings for father & & & 0.006 \\
\hline No & $95(77.9 \%)$ & $27(22.1 \%)$ & \\
\hline Yes & $14(50 \%)$ & $14(50 \%)$ & \\
\hline Subjective depressive feelings for wife & & & 0.12 \\
\hline No & $94(75.2 \%)$ & $31(24.8 \%)$ & \\
\hline Yes & $15(60 \%)$ & $10(40 \%)$ & \\
\hline Self-esteem issues & & & 0.012 \\
\hline No & $90(78.3 \%)$ & $25(21.7 \%)$ & \\
\hline To some extent & $11(47.8 \%)$ & $12(52.2 \%)$ & \\
\hline Yes & $8(66.7 \%)$ & $4(33.3 \%)$ & \\
\hline Father's social relationships & & & 0.872 \\
\hline Weak & $1(100 \%)$ & $0(0 \%)$ & \\
\hline Average & $16(66.7 \%)$ & $8(33.3 \%)$ & \\
\hline Good & $35(72.9 \%)$ & $13(27.1 \%)$ & \\
\hline Excellent & $57(74 \%)$ & $20(26 \%)$ & \\
\hline Relationship with the wife & & & 0.001 \\
\hline Weak & $0(0 \%)$ & $2(100 \%)$ & \\
\hline Average & $9(90 \%)$ & $1(10 \%)$ & \\
\hline Good & $13(48.1 \%)$ & $14(51.9 \%)$ & \\
\hline Excellent & $78(78.4 \%)$ & $24(21.6 \%)$ & \\
\hline Multiple wives & & & 0.728 \\
\hline No & $101(72.1 \%)$ & $39(27.9 \%)$ & \\
\hline Yes & $8(80 \%)$ & $2(20.0 \%)$ & \\
\hline Other family members living with husband and wife & & & 0.619 \\
\hline No & $89(73.6 \%)$ & $32(26.4 \%)$ & \\
\hline
\end{tabular}

J Mens Health Vol 16(1):e41-e52; 19 March 2020

This article is distributed under the terms of the Creative Commons Attribution-Non

Commercial 4.0 International License. (C2020 Alghamdi et al. 
TABLE 1. Related to Paternal Postpartum Depression Measured Using Chi-Squared Test ( $\mathrm{n}=150)$ (Continued)

\begin{tabular}{|c|c|c|c|}
\hline \multirow{3}{*}{ Studied factors } & \multicolumn{2}{|c|}{ PPPD (\% within factor) } & \multirow{3}{*}{ p-value } \\
\hline & $\begin{array}{c}\text { No depression } \\
\text { based on EPDS }\end{array}$ & $\begin{array}{c}\text { Depression } \\
\text { based on EPDS }\end{array}$ & \\
\hline & $(n=109,72.7 \%)$ & $(n=41,27.3 \%)$ & \\
\hline Yes & $20(69 \%)$ & $9(31.0 \%)$ & \\
\hline Sleep problems & & & 0.01 \\
\hline Never & $53(84.1 \%)$ & $10(15.9 \%)$ & \\
\hline Rarely & $13(76.5 \%)$ & $4(34.5 \%)$ & \\
\hline Sometimes & $30(68.2 \%)$ & $14(31.8 \%)$ & \\
\hline Always & $13(50 \%)$ & $13(50 \%)$ & \\
\hline Family-related problems & & & 0.00001 \\
\hline No & $106(78.5 \%)$ & $29(21.5 \%)$ & \\
\hline Yes & $3(20 \%)$ & $12(80 \%)$ & \\
\hline Work-related problems & & & 0.002 \\
\hline No & $97(78.2 \%)$ & $27(21.8 \%)$ & \\
\hline Yes & $12(46.2 \%)$ & $14(53.8 \%)$ & \\
\hline Family-work conflict & & & 0.000034 \\
\hline No & $93(81.6 \%)$ & $21(18.4 \%)$ & \\
\hline Yes & $16(44.4 \%)$ & $20(55.6 \%)$ & \\
\hline Father health problems & & & 0.437 \\
\hline No & $87(71.3 \%)$ & $35(28.7 \%)$ & \\
\hline Yes & $22(78.6 \%)$ & $6(21.4)$ & \\
\hline Newborn health problems & & & 1 \\
\hline No & $101(72.7 \%)$ & $38(27.3 \%)$ & \\
\hline Yes & $8(72.7 \%)$ & $3(27.3 \%)$ & \\
\hline Perceived stress during pregnancy & & & 0.001 \\
\hline Never & $57(78.1 \%)$ & $16(21.9 \%)$ & \\
\hline Rarely & $22(87.5 \%)$ & $4(12.5 \%)$ & \\
\hline Sometimes & $20(60.6 \%)$ & $13(39.4 \%)$ & \\
\hline Always & $4(33.3 \%)$ & $8(66.7 \%)$ & \\
\hline Perceived stress postpartum & & & 0.00002 \\
\hline Never & $84(82.4 \%)$ & $18(17.6 \%)$ & \\
\hline Rarely & $14(73.3 \%)$ & $5(26.3 \%)$ & \\
\hline Sometimes & $11(42.3 \%)$ & $15(57.7 \%)$ & \\
\hline Always & $0(0 \%)$ & $3(100 \%)$ & \\
\hline Knowledge of infant's health from medical staff & & & 0.047 \\
\hline No & $22(61.6 \%)$ & $14(38.9 \%)$ & \\
\hline
\end{tabular}

J Mens Health Vol 16(1):e41-e52; 19 March 2020

This article is distributed under the terms of the Creative Commons Attribution-Non Commercial 4.0 International License. (C2020 Alghamdi et al. 
TABLE 1. Related to Paternal Postpartum Depression Measured Using Chi-Squared Test ( $\mathrm{n}=150)$ (Continued)

\begin{tabular}{|c|c|c|c|}
\hline \multirow{3}{*}{ Studied factors } & \multicolumn{2}{|c|}{ PPPD (\% within factor) } & \multirow{3}{*}{ p-value } \\
\hline & $\begin{array}{l}\text { No depression } \\
\text { based on EPDS }\end{array}$ & $\begin{array}{c}\text { Depression } \\
\text { based on EPDS }\end{array}$ & \\
\hline & $(n=109,72.7 \%)$ & $(n=41,27.3 \%)$ & \\
\hline To some extent & $15(62.5 \%)$ & $9(37.5 \%)$ & \\
\hline Yes & $72(80 \%)$ & $18(20 \%)$ & \\
\hline Knowledge of wife's health from medical staff & & & 0.038 \\
\hline No & $22(57.9 \%)$ & $16(42.1 \%)$ & \\
\hline To some extent & $16(69.6 \%)$ & $7(30.4 \%)$ & \\
\hline Yes & $71(79.8 \%)$ & $18(20.2 \%)$ & \\
\hline Was pregnancy planned & & & 0.881 \\
\hline No & $57(72.2 \%)$ & $22(27.8 \%)$ & \\
\hline Yes & $52(73.2 \%)$ & $19(26.8 \%)$ & \\
\hline Preference of infant's gender & & & 0.762 \\
\hline Male & $32(76.2 \%)$ & $10(23.8 \%)$ & \\
\hline Female & $17(68 \%)$ & $8(32 \%)$ & \\
\hline Neither & $60(72.7 \%)$ & $23(27.7)$ & \\
\hline Newborn gender & & & 0.877 \\
\hline Male & $53(74.6 \%)$ & $18(25.4 \%)$ & \\
\hline Female & $53(70.7 \%)$ & $22(29.3 \%)$ & \\
\hline Twins & $3(75 \%)$ & $1(25 \%)$ & \\
\hline
\end{tabular}

PPPD, Paternal postpartum depression; EPDS, Edinburgh Postnatal Depression Scale.

during the postpartum period from the 4 th to the 8 th week. Our results revealed that the prevalence of PPPD in our sample was $27.3 \%$, based on the cutoff score of $>10$ points in the EPDS. The prevalence of $27.3 \%$ is high, compared to most previous international studies ${ }^{7}$; however, Philpott and Corcoran $^{24}$ found a similar prevalence rate $(28 \%)$ in Ireland. In their study, however, the EPDS cutoff score was set at 9 instead of 10 .

The significant factors concerning fathers with PPPD include a poor relationship with the partner/infant's mother, trouble sleeping, workrelated problems, work-family conflict, history of depression in partner/infant's mother, subjective depressive feeling in father, perceived stress - in both perinatal and postnatal periods - and poor knowledge regarding partner and infant's health while in the hospital.

While it has been documented that younger fathers are at increased risk of depressive symptoms, ${ }^{25}$ our results did not show any significant association between age and an increased risk of PPPD. This finding is similar to the findings of Cameron et al. and Gawlik et al. ${ }^{7,26}$ Gwalik et al. also documented that low income, low level of education, and poor relationship quality increased the risk of PPPD. Our study showed a positive association with poor relationship quality with the partner/ infant's mother, which is similar to the results of Zhang et al.'s study in northwestern China ${ }^{27}$; however, there were no other significant 
TABLE 2 Factors Significantly Correlated with Paternal Postpartum Depression Measured Using a Chi-Squared Test $(n=150)$

\begin{tabular}{|l|c|}
\hline Studied factors & p-value \\
\hline Relationship with the wife & 0.001 \\
\hline Sleep problems & 0.010 \\
\hline Self-esteem issues & 0.012 \\
\hline Family-related problems & 0.00001 \\
\hline Work-related problems & 0.002 \\
\hline Family-work conflict & 0.000034 \\
\hline Wife previously diagnosed with depression & 0.020 \\
\hline Subjective depressive feelings (father) & 0.006 \\
\hline Perceived stress in pregnancy & 0.001 \\
\hline Perceived stress postpartum & 0.00002 \\
\hline $\begin{array}{l}\text { Knowledge of infant's health from } \\
\text { medical staff }\end{array}$ & 0.047 \\
\hline $\begin{array}{l}\text { Knowledge of wife's health from } \\
\text { medical staff }\end{array}$ & 0.038 \\
\hline
\end{tabular}

similarities between the results from the two studies.

In Cameron et al.'s meta-analysis, ${ }^{7}$ the sociodemographic variables were not conditional for depressive symptoms. Our study had similar findings in that age, nationality, marital status, city of residence, level of education, monthly income, occupation, hours worked per day, and whether the father took paternal leave showed no positive association with PPPD. The supplementary articles by Nelson and Guyer and Nishimura and Ohashi ${ }^{28,29}$ showed that occupation had a positive association with work status, signifying that unemployment was a risk factor. Our research also showed a strong association between PPPD and work-family conflict and work-related problems, although no existing study was found to corroborate this result. The pressure of providing for a new family member will likely place an additional burden on the father, especially if he was the sole provider. However, according to Nishimura and Ohashi's study in Japan, ${ }^{29}$ not enough data are available to confirm this association. Moreover,
Nishimura and Ohashi's study ${ }^{29}$ also stated that emotional problems between the father and the partner/infant's mother is a risk factor. This supports our results, which showed an association between a poor relationship with partner/infant's mother and PPPD. Lastly, we also found a positive correlation between PPPD and the partner/ infant's mother's previous depression, which could be in relation to previous marital dissatisfaction for spouses of depressed persons. Literature showed increase of marital discord when one of the partners' is depressed. ${ }^{30,31}$ However, we weren't able to find anything that reflects on our findings, which calls for further investigations related to the marital outcome of PPD.

The factors related directly to the fathersuch as subjective depressive feelings, trouble sleeping, and self-esteem problems-all had a positive association with PPPD and are plausible risk factors for PPPD. Nevertheless, further research is needed to validate these results. Moreover, considering the factors of medical or surgical health problems, the results are relatively insignificant. A study by Gawlik et al. ${ }^{26}$ implied that preparing for the upcoming life changes associated with a newborn could somewhat alleviate PPPD; however, our study showed that perceived stress - in both perinatal and postpartum periods - is also strongly correlated with PPPD.

As the notion of PPPD becomes more prevalent and mainstream, prevention and intervention are both needed to deal with this rising dilemma. There are several ways to prevent PPPD, starting with educating both parents regarding the subject, that not only the mother is vulnerable to this condition, but so is the father. Raising awareness, providing educational classes or pamphlets might also decrease the stigma, as well as provide the opportunity to discuss the symptomatology that may accompany it. ${ }^{32}$ A study conducted by Suto et $a 1 .^{33}$ reported that screening fathers at risk during the perinatal period may provide greater insight into the fathers condition to the 
practitioners managing the family, in addition to providing an early intervention to help halt the progress of the condition. Managing cases of PPPD still requires more evidence for the most optimal management. It might be helpful to start the father on pharmacological or psychological therapies, but as Musser et al. ${ }^{34}$ mentioned, the most effective way to deal with PPPD is focusing on cause(s) that might be triggering it.

There are, of course, certain limitations to this study. First, the cross-sectional nature of the study makes it impossible to ascertain the onset of PPPD in the study sample, the possible causality between the presumed risk factors and PPPD, or whether participants experienced PPPD beyond the 1-2 month postpartum period that this study targeted. The second limitation is the relatively small sample size, drawn from only one medical center. The reason for the small study size is that our study is a pilot study for the particular region. Future studies should therefore follow a prospective design, preferably starting at pre-pregnancy and running up to 6 months postpartum. There should also be a multi-center study to more confidently assess the prevalence and risk factors of PPPD.

The third limitation was that the EPDS was not applied to the mothers to identify current PPD and to correlate with PPPD. The importance of this factor has been highlighted in previous studies. ${ }^{8}$ Instead, we asked the father about his perception of the mother's mood and whether she was ever diagnosed with major depression disorder or PPD. The fourth limitation is that we did not implement a full face-to-face psychological evaluation. Instead, the questionnaire was completed telephonically by the father. Carrying out the face-to-face evaluation could have been valuable to further investigate and verify the results of the EPDS. The last notable limitation is that a considerable number of fathers refused to be enrolled in the study due to the sensitivity of the subject, and only Arabic speakers could be included. This influenced the size of our study sample. At the outset, we attempted to measure religiosity using the Duke University Religiosity Index, ${ }^{35}$ as religiosity and spirituality are observed factors in the development of depression and PPD. ${ }^{36,37}$ However, many respondents refused to complete it for reasons of privacy or because it is unusual to deviate from cultural norms regarding religion and spirituality.

\section{CONCLUSION}

Our findings confirm that PPPD is prevalent in the study area. PPPD screenings and treatment are currently lacking and there is an urgent need to improve these factors, especially considering risk factors such as a maternal history of depression and poor work or family status. Counselling and support for managing health, family, and work issues - both perinatal and postpartumcould contribute to preventing PPPD. We recommend prospective and multi-center studies for better assessment of PPPD in the Middle East.

\section{CONFLICT OF INTEREST}

The authors have declared that they have no conflicts of interest.

\section{FUNDING}

This research received no external funding.

\section{REFERENCES}

1. World Health Organization. Fact sheet: Depression, 2018 [Internet]. [cited 2018 June 30]. Available from: http://www.who.int/mediacentre/factsheets/fs369/en/

2. World Health Organization. Depression: A global crisis. World Mental Health Day. Occoquan, VA: World Federation for Mental Health; 2012.

3. Peluso, ÉD, Blay, SL. Public stigma in relation to individuals with depression. $\mathrm{J}$ Affect Disord 2009;115(1-2):201-6. https://doi.org/10.1016/j.jad. 2008.08.013

4. Rogge, T. Postpartum depression. U.S. National Library of Medicine, 2014 [Internet]. [cited 2018 June 30]. Available from: https://www.nlm.nih. gov/medlineplus/ency/article/007215.htm 
5. Ko JY, Rockhill KM, Tong VT, et al. Trends in postpartum depressive symptoms - 27 states, 2004, 2008, and 2012. MMWR Morb Mortal Wkly Rep 2017;66(6):153. https://doi.org/10. 15585/mmwr.mm6606a1

6. Letourneau N, Duffett-Leger L, Dennis CL, et al. Identifying the support needs of fathers affected by post-partum depression: A pilot study. J Psychiatr Ment Health Nurs 2011;18:41-7. https://doi.org/ 10.1111/j.1365-2850.2010.01627.x

7. Cameron EE, Sedov ID, Tomfohr-Madsen LM. Prevalence of paternal depression in pregnancy and the postpartum: An updated meta-analysis. J Affect Disord 2016;206:189-203. https://doi. org/10.1016/j.jad.2016.07.044

8. Paulson JF, Bazemore SD. Prenatal and postpartum depression in fathers and its association with maternal depression: A meta-analysis. JAMA 2010;303(19):1961-9. https://doi.org/ 10.1001/jama.2010.605

9. Kim P, Swain JE. Sad dads: Paternal postpartum depression. Psychiatry (Edgmont) 2007;4(2):35.

10. Koh YW, Chui CY, Tang CS, Lee AM. The prevalence and risk factors of paternal depression from the antenatal to the postpartum period and the relationships between antenatal and postpartum depression among fathers in Hong Kong. Dep Res Treat 2014;2014:1-11. https://doi.org/ 10.1155/2014/127632

11. Anding JE, Röhrle B, Grieshop M, et al. Couple comorbidity and correlates of postnatal depressive symptoms in mothers and fathers in the first two weeks following delivery. J Affect Disord 2016;190:300-9. https://doi.org/10.1016/j.jad.2015. 10.033

12. Feldman R. Infant-mother and infant-father synchrony: The coregulation of positive arousal. Infant Ment Health J 2003;24(1):1-23. https:// doi.org/10.1002/imhj.10041

13. Ramchandani P, Stein A, Evans J, et al. Paternal depression in the postnatal period and child development: A prospective population study. Lancet 2005;365(9478):2201-5. https://doi.org/10.1016/ S0140-6736(05)66778-5

14. Eiden RD, Edwards EP, Leonard KE. Motherinfant and father-infant attachment among alcoholic families. Dev Psychopathol 2002;14(2):253-78. S0954579402002043

15. Morse CA, Buist A, Durkin S. First-time parenthood: Influences on pre- and postnatal adjustment in fathers and mothers. J Psychosom Obstet Gynaecol 2000;21(2):109-20. https://doi. org/10.3109/01674820009075616

16. Martins C, Gaffan EA. Effects of early maternal depression on patterns of infant-mother attachment: A meta-analytic investigation. J Child Psychol Psychiatry 2000;41(6):737-46. https://doi.org/ 10.1111/1469-7610.00661

17. Shaheen NA, AlAtiq Y, Thomas A, et al. Paternal postnatal depression among fathers of newborn in Saudi Arabia. Am J Men's Health 2019;13(1): 1557988319831219. https://doi.org/10.1177/15579 88319831219

18. Moussa S, Emad M, Khoweiled A, et al. Antenatal depression in expectant fathers (an Egyptian study). Egypt J Psychiatry 2012;33:90-6. https:// doi.org/10.7123/01.EJP.0000413118.03956.0b

19. Alamri Y. Mental illness in Saudi Arabia: Stigma and acceptability. Int J Soc Psychiatry 2016;62(3):306-7. https://doi.org/10.1177/0020 764016628896

20. Sewilam AM, Watson AM, Kassem AM, et al. Suggested avenues to reduce the stigma of mental illness in the Middle East. Int J Soc Psychiatry 2015;61(2):111-20.https://doi.org/10.1177/ 0020764014537234

21. Zubaran C, Schumacher M, Roxo MR, Foresti K. Screening tools for postpartum depression: Validity and cultural dimensions. Afr J Psychiatry (Johannesbg) 2010;13(5):357-65. https://doi.org/ 10.4314/ajpsy.v13i5.63101

22. Edmondson O JH, Psychogiou L, Vlachos H, et al. Depression in fathers in the postnatal period: Assessment of the Edinburgh Postnatal Depression Scale as a screening measure. J Affect Disord 2010;125(1-3):365-8. https://doi.org/10.1016/j.jad. 2010.01.069

23. Ghubash R, Abou-Saleh MT, Daradkeh TK. The validity of the Arabic Edinburgh postnatal depression scale. Soc Psychiatry Psychiatr Epidemiol 1997;32(8):474-6. 
24. Philpott LF, Corcoran P. Paternal postnatal depression in Ireland: Prevalence and associated factors. Midwifery 2018;56:121-7. https://doi. org/10.1016/j.midw.2017.10.009

25. Bergström M. Depressive symptoms in new firsttime fathers: Associations with age, sociodemographic characteristics, and antenatal psychological well-being. Birth 2013;40(1):32-8. https://doi.org/ 10.1111/birt.12026

26. Gawlik S, Müller M, Hoffmann L, et al. Prevalence of paternal perinatal depressiveness and its link to partnership satisfaction and birth concerns. Arch Womens Ment Health 2014;17(1):49-56. https://doi.org/10.1007/s00737-013-0377-4

27. Zhang YP, Zhang LL, Wei HH, et al. Post partum depression and the psychosocial predictors in firsttime fathers from northwestern China. Midwifery 2016;35:47-52. https://doi.org/10.1016/j.midw. 2016.01.005

28. Nelson EE, Guyer AE. Postnatal depression in Mexican American fathers: Demographic, cultural, and familial predictors. J Affect Disord 2012;1(3):233-45.

29. Nishimura A, Ohashi K. Risk factors of paternal depression in the early postnatal period in Japan. Nurs Health Sci 2010;12(2):170-6. https://doi. org/10.1111/j.1442-2018.2010.00513.x

30. Whisman MA, Uebelacker LA. Prospective associations between marital discord and depressive symptoms in middle-aged and older adults. Psychol
Aging 2009;24(1):184-9. https://doi.org/10.1037/ a0014759

31. Benazon NR, Coyne JC. Living with a depressed spouse. J Fam Psychol 2000;14(1):71-9. https:// doi.org/10.1037/0893-3200.14.1.71

32. Stadtlander L. Paternal postpartum depression. Int J Childbirth Education 2015;30:11-13.

33. Suto M, Isogai E, Mizutani F, et al. Prevalence and factors associated with postpartum depression in fathers: A regional, longitudinal study in Japan. Res Nurs Health 2016;39:253-62. https:// doi.org/10.1002/nur.21728

34. Musser A, Ahmed A, Foli K, et al. Paternal postpartum depression: What health care providers should know. J Pediatr Health Care 2012;27:479-85. https://doi.org/10.1016/j.pedhc.2012.10.001

35. Koenig HG, Meador KG, Parkerson G. Religion index for psychiatric research. Am J Psychiatry 1997;154:885-6. https://doi.org/10.1037/t04429-000

36. Mann JR, McKeown RE, Bacon J, et al. Religiosity, spirituality, and depressive symptoms in pregnant women. Int J Psychiatry Med 2007;37(3):301-13. https://doi.org/10.2190/PM.37.3.g

37. Lara-Cinisomo S, Wood J, Fujimoto EM. A systematic review of cultural orientation and perinatal depression in Latina women: Are acculturation, Marianismo, and religiosity risks or protective factors? Arch Womens Ment Health 2018;557-67. https://doi.org/10.1007/ s00737-018-0920-4 